Original Research Article

\title{
A prospective study to assess the adverse events following immunization in paediatric population
}

\author{
Ambrish Gupta ${ }^{1}$, Prashant Maheshwari2*, Y. K. Rao ${ }^{3}$
}

${ }^{1}$ Department of Pharmacology, G.S.V.M. Medical College, Kanpur, Uttar Pradesh, India ${ }^{2}$ Drug Safety Physician, Rainbow Medical Centre, Kanpur, Uttar Pradesh, India ${ }^{3}$ Department of Paediatrics, G.S.V.M. Medical College, Kanpur, Uttar Pradesh, India

Received: 12 November 2017 Accepted: 17 November 2017

\section{*Correspondence to:}

Dr. Prashant Maheshwari, Email: drmaheshwari.2012@ hotmail.com

Copyright: (C) the author(s), publisher and licensee Medip Academy. This is an openaccess article distributed under the terms of the Creative Commons Attribution NonCommercial License, which permits unrestricted noncommercial use, distribution, and reproduction in any medium, provided the original work is properly cited.

\begin{abstract}
Background: The objective of current study was to analyse the pattern of adverse drug reactions due to different vaccines in paediatric patients.

Methods: A prospective observational study was carried out in paediatric department of GSVM medical college Kanpur to monitor vaccine adverse event and its causal as sociation with vaccine. Patients of 0-10 year age group of either sex, who developed adverse event following vaccination, were included in study. Vaccine adverse event were recorded in the suspected ADRs reporting form of Indian Pharmacopoeia commission. Causality was evaluated using WHO-UMC assessment scale, outcome and seriousness as per W.H.O. To classify type of ADRs, Expanded Rawlins- Thompson's classification systemwas used.

Results: Vaccine adverse reactions were more in female (53\%) as compared to male (47\%). Most common age group involved was $0-6$ months; $(79.41 \%)$ of total reactions. Fever $(14.70 \%)$ was most common reaction, followed by pain at inj. site $(11.77 \%)$, and Convulsion (11.77). The causality of $67.65 \%$ vaccine adverse reactions was of possible type; $88.23 \%$ reactions were of non-serious type. Type A reaction were more common and most of vaccine adverse reaction recovered $(82.35 \%)$.

Conclusions: Vaccines can also cause different types of adverse reactions in paediatric patients. This Study emphasizes the need for an effective vaccine adverse event monitoring system among paediatric patients in every hospital to ensure safety of vaccine. Hence more educational awareness program should be plotted and more similar studies are needed to be conducted.
\end{abstract}

Keywords: Adverse reactions, Causality, Paediatric patients, Vaccine

\section{INTRODUCTION}

Immunization is perhaps the greatest public health achievement of all time, having significantly reduced the morbidity and mortality of many infectious diseases. Routine immunization of children, adolescents, and adults provides substantial protection from a large number of infectious diseases. ${ }^{1}$

\section{Vaccine pharmacovigilance}

Vaccine pharmacovigilance is defined as-the science and activities relating to the detection, assessment, understanding and communication of adverse events following immunization and other vaccine- or immunization-related issues, and to the prevention of untoward effects of the vaccine or immunization. ${ }^{2}$ All medicines have side effects; however, vaccines are among the safest and the benefits of vaccinations far outweigh the risk of side effects. It is highly important to identify vaccine reactions that are causally related to the vaccine (vaccine adverse reactions) from other adverse events so that compliance to vaccines does not drop. Vaccine adverse reactions are basically those that are causally related to vaccines. 


\section{Classification of vaccine adverse reaction}

Classification of vaccine adverse reaction as local, systemic or allergic as follows: ${ }^{3}$

- Local reactions: Most parenteral vaccines induce some degree of local reactions including pain, erythema and induration. Local reactions may be partly ameliorated by ice application and paracetamol.

- Systemic reactions: Fever is the most common systemic reactions. Administration of paracetamol at the time of vaccination and later on a regular basis is helpful.

- Severe allergy: Severe allergy or anaphylaxis or anaphylaxis like reactions including generalized urticaria or hives, wheezing, swelling of the mouth and throat, difficulty breathing, hypotension, and shock occur rarely at a frequency of 1 per $10,00,000$ vaccines. These reactions are rarely due to the vaccine antigen; they are usually due to other vaccine constituents including residual animal protein, stabilizers, antimicrobials or preservatives.

Mild local reactions and fever after vaccinations are common and do not contraindicate future doses. Anaphylactic reactions to vaccines are rare and should be evaluated with skin tests to the vaccine and its components. If the skin test results are negative, subsequent doses can be administered in the usual manner but under observation. If the skin test results are positive and the patient requires subsequent doses, the vaccine can be administered in graded doses under observation. Some non-anaphylactic reactions to vaccines might also require evaluation, but only a few are contraindications to future doses. ${ }^{4}$ Although there are some adverse reactions to vaccines that constitute absolute contraindications to administration of future doses, most such reactions do not preclude subsequent immunization. ${ }^{5}$ Patients who have experienced an apparent allergic or other serious adverse reaction after receiving a vaccine warrant evaluation by an allergist/immunologist. Vaccines are not free from side effects, or - adverse effects, but most are very rare or very mild. Importantly, some adverse health problems following a vaccine may be due to coincidence and are not caused by the vaccine. As part of the evaluation of vaccines over time, researchers assess evidence to determine if adverse events following vaccination are causally linked to a specific vaccine, and if so, they are referred to as adverse effects. ${ }^{6}$ A vaccine is a medical product. Vaccines, though they are designed to protect from disease, can cause side effects, just as any medication can. A possible side effect resulting from a vaccination is known as an adverse event. Most side effects from vaccination are mild, such as soreness, swelling, or redness at the injection site. Some vaccines are associated with fever and rash. Serious side effects are rare, but may include seizure or life-threatening allergic reaction. Hence present study was designed to assess the vaccine adverse events in pediatric population and relatedness of vaccine with the adverse events.

\section{METHODS}

Children who came for immunization in department of paediatrics, G.S.V.M. Medical College, Kanpur, U.P.

A prospective observational study was carried out at inpatient and out-patient setting in paediatric department of GSVM medical college Kanpur U.P for a period of 3 months.

\section{Inclusion criteria}

Patients between 0-10 year age group; of either sex, who came for immunization and developed suspected adverse event following vaccination, were included in our study.

\section{Exclusion criteria}

Patients with any other co-morbid illness, not willing to give consent; were excluded from our study.

After enrolling the patients in study relevant data was collected and analysed for different aspects pertinent to adverse drug reactions.

\section{Data collection and analysis}

Patient's demographic details like patient initial, OPD/IPD number, age, sex, medical history, medication history, allergies etc was recorded from patients file.

If there was any adverse event following vaccination, event was recorded on ADRs reporting form provided by Indian Pharmacopoeia commission. After recording the adverse event; each event was analysed for the following parameters by using different scales. These are as follows :

- $\quad$ Causality - By W.H.O-UMC causality scale.

- Type of ADR: As per Expanded RawlinsThompson's classification.

- Outcome and Seriousness: As per criteria given by W.H.O.

- Predictability: As per guidelines given by Council for International Organization of Medical Science (CIOMS).

- Severity: All ADRs were categorized as mild, moderate and severe according to Modified Hartwig Severity levels.

\section{RESULTS}

Total number of vaccine associated ADRs was 34; from the 26 patients, in the present study.

Distribution of Vaccine adverse reaction was more in female $(53 \%)$ as compared to male (47\%) and most common age group was $0-6$ months with $79.41 \%$ of total 
reactions followed by 6 months- 1 year age group $(11.76 \%)$ and $>1$ year age group $(8.83 \%)$ (Table 1$)$.

Table 1: Demographic distribution of vaccine adverse reactions.

\begin{tabular}{|llll|}
\hline Gender & $\begin{array}{l}\text { No. of patients } \\
(\mathbf{N}=26)\end{array}$ & $\begin{array}{l}\text { No. of ADRs } \\
(\mathbf{N}=34)\end{array}$ & $\begin{array}{l}\% \text { OF } \\
\text { ADRs }\end{array}$ \\
\hline Male & 12 & 16 & $47 \%$ \\
\hline Female & 14 & 18 & $53 \%$ \\
\hline Age & & & $79.41 \%$ \\
\hline $\begin{array}{l}0-6 \\
\text { months }\end{array}$ & 21 & 27 & $11.76 \%$ \\
\hline $\begin{array}{l}\text { 6mth-1 } \\
\text { yr }\end{array}$ & 2 & 4 & $8.83 \%$ \\
\hline$>1 \mathrm{yr}$ & 3 & 3 & \\
\hline
\end{tabular}

Following immunization 15 different types of reactions developed. Out of all reactions; Fever (14.70 \%) was most common, followed by pain at injection site $(11.77 \%)$, Convulsion (11.77), sterile abscess $(8.83 \%)$, excessive crying (8.83\%), Rash (5.88\%), regurgitation (5.88\%), and lymph node enlargement $(5.88 \%)$ (Table 2$)$.

Table 2: Various types of vaccine associated adverse reactions.

\begin{tabular}{|llll|}
\hline & ADR & No. & $\%$ \\
\hline 1 & Fever & 5 & 14.7 \\
\hline 2 & Pain & 4 & 11.77 \\
\hline 3 & Convulsion & 4 & 11.77 \\
\hline 4 & Sterile abscess & 3 & 8.83 \\
\hline 5 & Excessive crying & 3 & 8.83 \\
\hline 6 & Rash & 2 & 5.88 \\
\hline 7 & Regurgitation & 2 & 5.88 \\
\hline 8 & Lymph node & 2 & 5.88 \\
\hline & enlargement & & \\
\hline 9 & Lump at inj. site & 2 & 5.88 \\
\hline 10 & Redness at inj. site & 2 & 5.88 \\
\hline 11 & Swelling in leg & 1 & 2.94 \\
\hline 12 & Fatigue & 1 & 2.94 \\
\hline 13 & Periorbital oedema & 1 & 2.94 \\
\hline 14 & Constipation & 1 & 2.94 \\
\hline 15 & Insomnia & 1 & 2.94 \\
\hline & Total & 34 \\
\hline
\end{tabular}

On causality assessment most of the reactions (67.65\%) were of possible type followed by probable $(32.35 \%)$. Most of the reactions (91.17\%) were of type-A followed by type-B $(8.83 \%)$; no $\mathrm{C}, \mathrm{D}, \mathrm{E}$ and $\mathrm{F}$ type reactions following immunization were found in the present study. Most of the reactions ( $88.23 \%$ ) were of non-serious type followed by serious reactions (11.77\%). Most of the reaction recovered $(82.35 \%)$ in due course in the present study. On severity assessment majority of reactions were of mild category $(52.9 \%)$ followed by moderate $(35.29 \%)$ and severe (11.7\%) (Figure 1 to Figure 5).

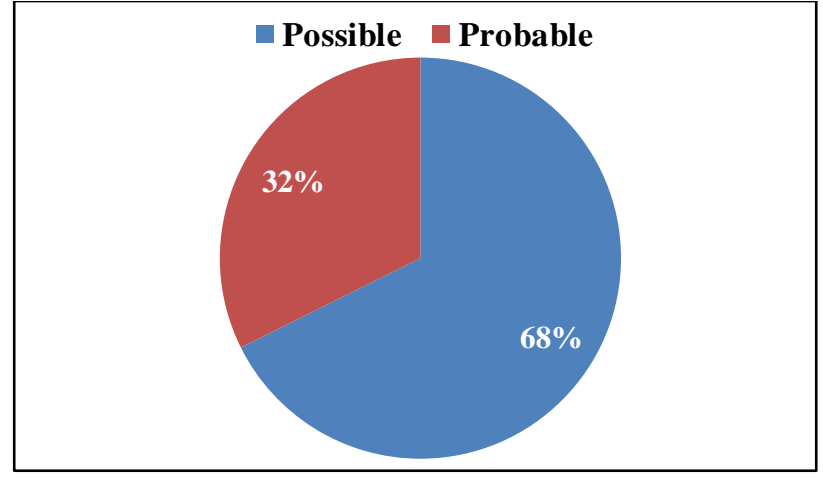

Figure 1: Causality assessment.

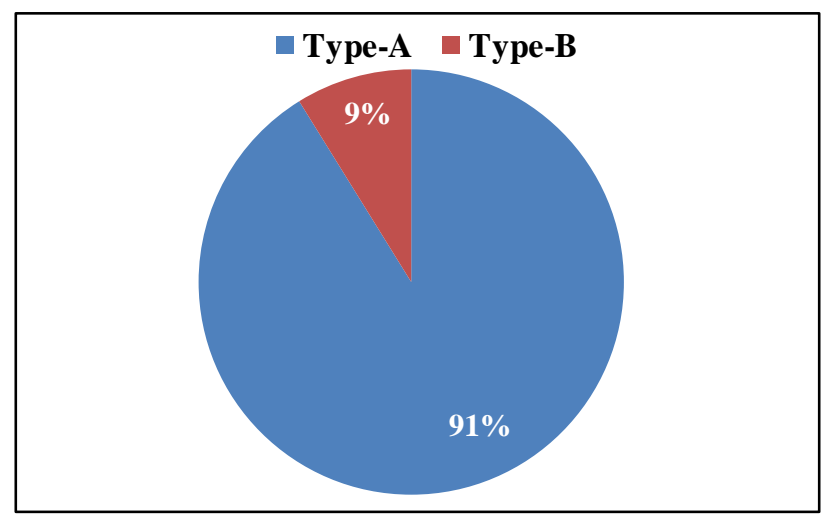

Figure 2: Type of ADRs.

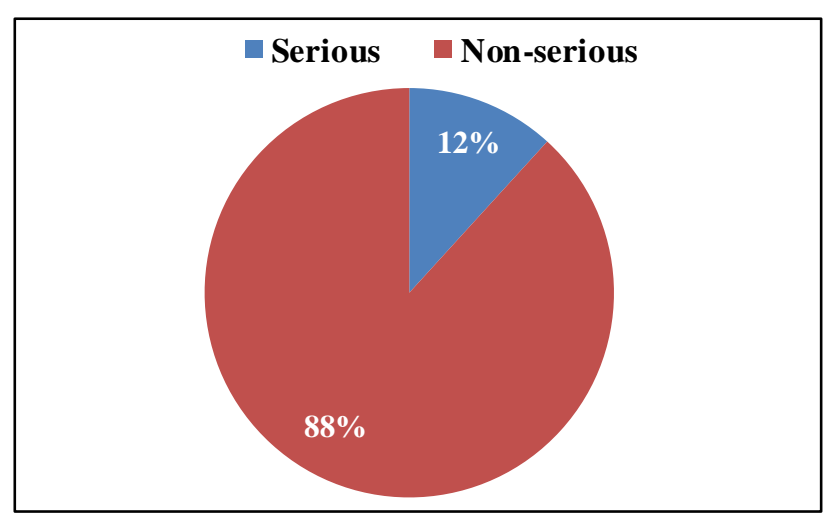

Figure 3: Seriousness of ADRs.

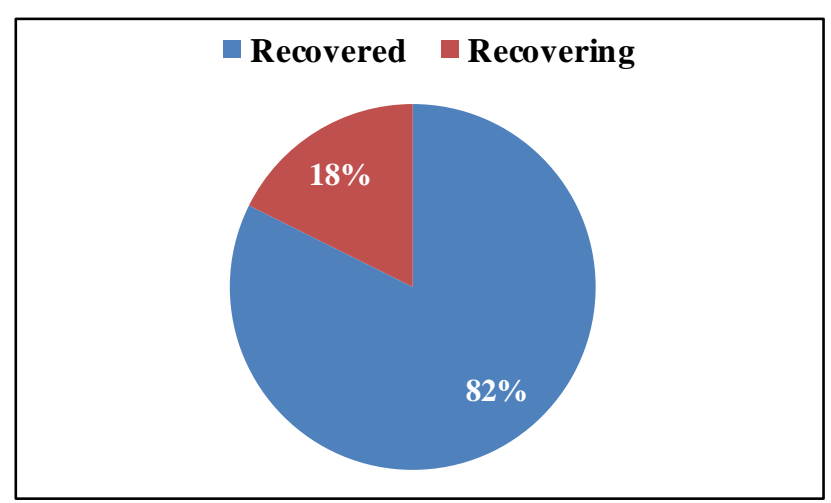

Figure 4: Outcome of ADRs. 


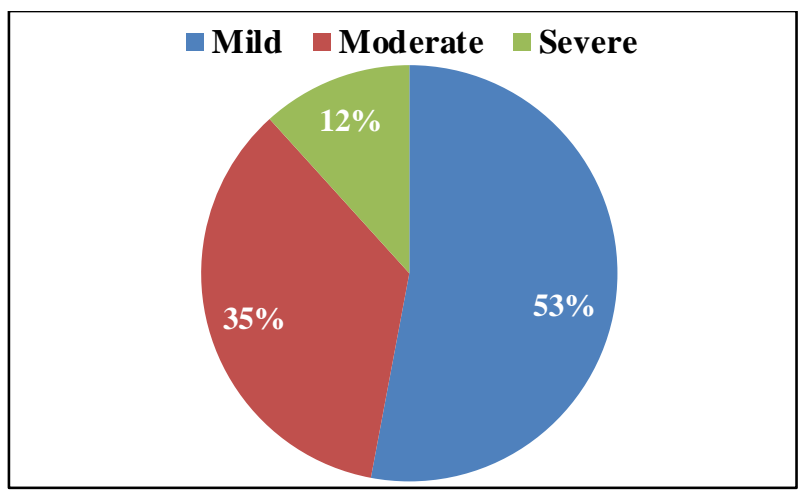

Figure 5: Causality assessment of ADRs.

Among Vaccines most of the reactions are associated with DPT vaccine $(38.30 \%)$ followed by Hepatitis - B vaccine (14.70\%), Tetanus toxoid $(14.70 \%),(11.75 \%)$ reactions each with MMR vaccine and BCG vaccine and only $8.8 \%$ reaction occurred following Pentavalent vaccine (Table 3 ).

Table 3: Associated adverse reactions with different vaccines.

\begin{tabular}{|lll|}
\hline Vaccine & No. of ADRs & $\%$ \\
\hline DPT & 13 & 38.3 \\
\hline Hep-B & 5 & 14.7 \\
\hline Tetan u s Toxoid & 5 & 14.7 \\
\hline MMR & 4 & 11.75 \\
\hline BCG & 4 & 11.75 \\
\hline Pentav alent & 3 & 8.8 \\
\hline Total & 34 & \\
\hline
\end{tabular}

\section{DISCUSSION}

The present study was conducted to assess the pattern of adverse events following vaccines administration. Six most common vaccines that lead to vaccine adverse reactions in paediatric patients were DPT, Hep-B, tetanus toxoid, MMR, BCG and pentavalent vaccine. In our study, the most common adverse event was fever. ${ }^{7-10}$ This study contrast with studies of authors and Carrasco-Garrido that describes swelling at the site of injection as the most common reaction following vaccination. ${ }^{11,12}$

DPT was the vaccine having the maximum number of vaccine adverse reactions. ${ }^{13,14}$ Present study is prospective, whereas studies carried by authors are retrospective. Most of vaccine adverse reactions occurred in age group below 6 months, quite similar to study conducted by Aherkar RY et al (showing below 1 year age group), as most of the doses are given in starting one year as per vaccination program. In present study most of the vaccine adverse reactions were of Type-A and of possible type on causality assessment, as de-challenge and re-challenge is not applicable in case of vaccines. Outcome of most of the reaction was found to be recovered, as these reactions are mostly of mild and non-serious nature.
This study has various limitations like short duration of study, limited population size and underreporting. Hence similar studies are needed to be executed on larger population and in different hospitals for satisfactory result related to vaccine safety.

\section{CONCLUSION}

This study reveals that on the one hand vaccines are associated with myriads of adverse reactions but on the other hand vaccines are ess ential for prevention of diseases under immunization programme. Although most of the vaccines associated adverse reactions were of mild and non-serious type, (rarely of serious nature) yet proper monitoring of vaccine associated adverse reactions; is too essential to prevent any kind of permanent damage or death.

\section{ACKNOWLEDGEMENTS}

Authors would like to thank I am highly thankful to my teacher Prof. I.P. Jain for guiding me and giving moral support; without them it was impossible to conduct this work in right direction.

\section{Funding: No funding sources Conflict of interest: None declared Ethical approval: Not required}

\section{REFERENCES}

1. Roush SW, Murphy TV. Historical comparisons of morbidity and mortality for vaccine-preventable diseases in the United States. JAMA. 2007;298:215563.

2. WHO. Report of CIOMS/WHO working group on vaccine pharmacovigilance: Definition and application of terms for vaccine pharmacovigilance, $2012 . \quad$ Available at: http://www.who.int/vaccine_safety/initiative/tools/CI OMS_report_WG_vaccine.pdf. Accessed 19 Nov 2017.

3. IAP. Guide book on immunization, 2014. Available at: http://www.iapindia.org/files/IAP-Gu idelines/IAPGuidebook-on-Immunization-2013-14.pdf. Accessed 19 Nov 2017

4. Kelso JM, Greenhawt MJ, Li JT, Nicklas RA, Bernstein DI, Blessing-Moore $\mathrm{J}$, et al. Adverse reactions to vaccines practice parameter 2012 update. Journal of Allergy and Clinical Immunology. $2012 \mathrm{Jul}$ $1 ; 130(1): 25-43$.

5. General recommendations on immunizationrecommendations of the Advisory Committee on Immunization Practices (ACIP). MMWR Morb Mortal Wkly Rep. 2011;60:1-64.

6. Institute of medicine of the national academies. Report: adverse effects of vaccines Evidence and causality, 2011. Available at: http://www.nationalacademies.org/hmd/ /media/Files /Report\%20Files/2011/Adverse-Effects-of-Vaccines- 
Evidence-and-Caus ality/Vaccine-report-brief-

FINAL.pdf. Accessed 19 Nov 2017.

7. Joshi ND, Prajapati HK, Solanki KC, Sukhlecha A, Trivedi HR, Gajera MV, et al. Pattern of adverse events following immunization in an Indian teaching hospital. IJMSPH. 2013;2(1):62-8.

8. Hu Y, Li Q, Lin L, Chen E, Chen Y, Qi X, et al. Surveillance for Adverse Events following Immunization from 2008 to 2011 in Zhejiang Province, China. Clin Vaccin Immunol. 2013;20(2):211-7.

9. Zhou W, Pool V, John K, English-Bullard R, Ball R, Wise RP, et al. Surveillance for safety after immunization: Vaccine Adverse Event Reporting System (VAERS): United States, 1991-2001MMW R Surveill Summ. 2003;52(1):1-24.

10. Zhang LP, Yu F, Jin BF, Wang Y, Xu HL, DU Y. Surveillance of adverse events following immunization in Minhang district of Shanghai from 2007 to 2010. Zhonghua $\mathrm{Er} \mathrm{Ke} \mathrm{Za}$ Zhi. 2012;50(11):859-64.
11. Mansoor O, Pillans PI. Vaccine adverse events reported in New Zealand 1990-5. N Z Med J. 1997;110(1048):270-2.

12. Carrasco-Garrido P, Gallardo-Pino C, Jiménez- García R, Tapias MA, de Miguel AG. Incidence of adverse reactions to vaccines in a paediatric population. Clin Drug Invest. 2004;24(8):457-63.

13. Aherkar RY, Deshpande PK, Ghongane BB. Study of the pattern of adverse events following immunization of children in a tertiary care hospital. International $\mathrm{J}$ of Basic \& Clinical Pharmacology. 2016;5(3):609-15.

14. Feery B. Incidence and type of reactions to triple antigen (DTP) and DT (CDT) vaccines, Medil J of Austr. 1982;2(11):511-5.

Cite this article as: Gupta A, Maheshwari P, Rao YK. A prospective study to assess the adverse events following immunization in paediatric population. Int J Basic Clin Pharmacol 2017;6:2827-31. 